PAPER

\title{
Schizophrenia-like psychosis arising de novo following a temporal lobectomy: timing and risk factors
}

\author{
P Shaw, J Mellers, M Henderson, C Polkey, A S David, B K Toone
}

J Neurol Neurosurg Psychiatry 2004;75:1003-1008. doi: 10.1136/jnnp.2003.022392

See end of article for authors' affiliations

......................

Correspondence to: Dr P Shaw, Department of Psychological Medicine, Institute of Psychiatry, 103 Denmark Hill, London, SE5 8AQ, UK; p.shaw@ iop.kcl.ac.uk

Received 3 July 2003 In revised form

3 September 2003

Accepted

11 September 2003

\begin{abstract}
Objectives: To clarify risk factors for the development of schizophrenia-like psychotic disorders following temporal lobectomy, and to explore the possibility that the early postoperative period is a time of high risk for the onset of such chronic psychotic disorders.

Methods: Patients who developed schizophrenia-like psychosis were identified from a series of 320 patients who had a temporal lobectomy for medically intractable epilepsy. The relationship of their disorders to both the operation and subsequent seizure activity was examined. Using a retrospective casecontrol design, risk factors for the development of schizophrenia-like psychosis were established.

Results: Eleven patients who developed schizophrenia-like psychosis postoperatively were identified and compared with 33 control subjects who remained free of psychosis postoperatively. The onset of de novo psychotic symptoms was typically in the first year following the operation. No clear relationship between postoperative seizure activity and fluctuations in psychotic symptoms emerged. Compared with the controls, patients who become psychotic had more preoperative bilateral electroencephalogram (EEG) abnormalities, pathologies other than mesial temporal sclerosis in the excised lobe and a smaller amygdala on the unoperated side.

Conclusions: Temporal lobectomy for medically intractable epilepsy may precipitate a schizophrenia-like psychosis. Patients with bilateral functional and structural abnormalities, particularly of the amygdala, may be at particular risk for the development of such psychoses.
\end{abstract}

\section{INTRODUCTION}

Several forms of psychotic disorders arise in association with epilepsy, including episodic seizure related psychoses and chronic interictal psychotic disorders which phenomenologically resemble schizophrenia. Psychotic disorders which follow a chronic interictal course and arise for the first time following a temporal lobectomy are of interest both as a potentially serious complication of the operation and for the insights they might provide into more common psychoses such as schizophrenia.

To date there are reports of just over 50 patients who developed de novo psychotic disorders following surgical treatment for medically intractable epilepsy. ${ }^{1-16}$ Although interpretation of the literature is complicated by the different definitions of psychosis used, several key issues of practical and theoretical importance have emerged. Firstly, several studies report a preponderance of congenital lesions, such as dysembryoblastic neuroepithelial tumours, in the excised lobe rather than the typical pathology of mesial temporal sclerosis which underlies most cases of temporal lobe epilepsy. ${ }^{6}{ }^{13}{ }^{17} 18$ There is also evidence of a clustering of the onset of the psychotic disorders in the early postoperative period. A review of studies done before 1997 reports that 11 of 23 cases of de novo psychosis started within six months of the temporal lobectomy. ${ }^{19}$ More recent work has confirmed this: Blumer et al ${ }^{12}$ describe six patients who developed psychosis within the first two postoperative months and Inoue and Mihara ${ }^{14}$ detail five cases that all arose in the first two years after the operation. Such temporal links provoke concerns about possible aetiological links between this operation and the development of psychosis. The pathophysiology of such an association could relate to changes in postoperative seizure activity. In a recent report of three patients who developed purely postictal psychosis, the psychosis followed the emergence of a new seizure type originating from the side contralateral to the operation. ${ }^{15}$ In all these cases there were preoperative bilateral electroencephalogram (EEG) abnormalities and the excision of the temporal lobe and development of new seizure activity may have acted upon a bilaterally compromised functional substrate prone to developing psychosis. We speculate that similar functional bilateral anomalies may be associated with the development of postoperative chronic schizophrenia-like psychosis. We also extend the previous work by examining patients for the presence of bilateral structural abnormalities.

The identification of risk factors for the development of psychosis post temporal lobectomy has potential therapeutic benefit as it would aid the early identification of those at high risk for developing the disorder.

We report on 11 subjects who developed psychotic disorders de novo following temporal lobectomy. We confined our study to patients who developed a chronic schizophrenia-like disorder and thus excluded purely postictal psychosis and depressive disorders with psychotic features. We describe the phenomenology of their disorders; the relationship between their surgery, subsequent seizure activity and psychotic symptoms; and identify risk factors for the development of psychosis.

\section{METHODS}

The study included 320 patients who underwent surgical treatment for medically intractable epilepsy at the Maudsley Hospital and King's College Hospital in London between 1978 and 2001. The preoperative protocols used in the epilepsy surgery centre have been described in detail elsewhere. ${ }^{20}$ In addition to interictal and awake EEG, most patients proceeded to ictal video-EEG recordings. Formal psychiatric evaluation is requested if there is evidence of a mental disorder either in the past or during the preoperative investigation period. In the patients with temporal lobe

Abbreviations: $\mathrm{Cl}$, confidence interval; DNET, dysembryoblastic neuroepithelial tumour; EEG, electroencephalogram; MTS, mesial temporal sclerosis; $O R$, odds ratio 
Table 1 Clinical features of patients who developed schizophrenia-like psychoses following surgical treatment for epilepsy

\begin{tabular}{|c|c|c|c|c|c|c|c|c|}
\hline Subject & Age/sex & Delusions & Hallucinations & First rank symptoms & $\begin{array}{l}\text { Thought } \\
\text { disorder }\end{array}$ & $\begin{array}{l}\text { Negative } \\
\text { symptoms }\end{array}$ & Course of disorder & $\begin{array}{l}\text { Duration of } \\
\text { symptoms }\end{array}$ \\
\hline $\mathrm{Pl}$ & $22 / M$ & Persecutory & $\begin{array}{l}\text { Auditory (2nd } \\
\text { person) }\end{array}$ & Thought insertion & Present & Apathy & $\begin{array}{l}\text { Chronic continuous } \\
\text { (no response to } \\
\text { treatment) }\end{array}$ & 10 yrs \\
\hline P2 & $20 / \mathrm{F}$ & Persecutory & $\begin{array}{l}\text { Auditory (2nd } \\
\text { person) }\end{array}$ & None & Present & $\begin{array}{l}\text { Social } \\
\text { withdrawal }\end{array}$ & $\begin{array}{l}\text { Chronic continuous } \\
\text { (partial control by } \\
\text { antipsychotics) }\end{array}$ & $14 \mathrm{yrs}$ \\
\hline P3 & $21 / M$ & $\begin{array}{l}\text { Persecutory } \\
\text { reference }\end{array}$ & None & None & Present & None & $\begin{array}{l}\text { Chronic continuous } \\
\text { (partial control on } \\
\text { antipsychotic) }\end{array}$ & 8 yrs \\
\hline P4 & $39 / \mathrm{F}$ & Persecutory & None & Somatic passivity & None & None & $\begin{array}{l}\text { Episodic with chronic } \\
\text { residual delusions } \\
\text { (partially responsive } \\
\text { to treatment) }\end{array}$ & 3 yrs \\
\hline P5 & $39 / M$ & Persecutory & None & None & Present & $\begin{array}{l}\text { Social } \\
\text { withdrawal }\end{array}$ & $\begin{array}{l}\text { Chronic continuous } \\
\text { (refused treatment) }\end{array}$ & $9 \mathrm{yrs}$ \\
\hline P6 & $18 / M$ & Persecutory & $\begin{array}{l}\text { Auditory (2nd } \\
\text { person) }\end{array}$ & None & None & $\begin{array}{l}\text { Emotional } \\
\text { flattening }\end{array}$ & $\begin{array}{l}\text { Chronic continuous } \\
\text { (poorly responsive to } \\
\text { antipsychotics) }\end{array}$ & 8 yrs \\
\hline P7 & $19 / M$ & Persecutory & Somatic & Thought insertion & None & None & $\begin{array}{l}\text { Chronic continuous } \\
\text { (refused medication) }\end{array}$ & $4 \mathrm{yrs}$ \\
\hline P8 & $33 / F$ & Persecutory & $\begin{array}{l}\text { Auditory (2nd } \\
\text { person) }\end{array}$ & None & None & None & $\begin{array}{l}\text { Episodic with minimal } \\
\text { symptoms between } \\
\text { episodes on } \\
\text { mediation }\end{array}$ & $\begin{array}{l}\text { Episodes last } \\
3-8 \mathrm{mths}\end{array}$ \\
\hline P9 & $19 / \mathrm{F}$ & Persecutory & $\begin{array}{l}\text { Auditory (2nd } \\
\text { person) }\end{array}$ & Somatic passivity & None & None & $\begin{array}{l}\text { Episodic with } \\
\text { complete recovery } \\
\text { between episodes on } \\
\text { antipsychotic } \\
\text { medication. } \\
\text { Intermittently compliant } \\
\text { with medication. }\end{array}$ & $16 \mathrm{yrs}$ \\
\hline P10 & $34 / F$ & $\begin{array}{l}\text { Persecutory and } \\
\text { reference }\end{array}$ & $\begin{array}{l}\text { Auditory (2nd } \\
\text { person) }\end{array}$ & None & Present & None & $\begin{array}{l}\text { One prolonged episode } \\
\text { (partially responsive to } \\
\text { antipsychotics) }\end{array}$ & 2 yrs \\
\hline P11 & $18 / F$ & Persecutory & $\begin{array}{l}\text { Auditory (3rd } \\
\text { person) }\end{array}$ & $\begin{array}{l}\text { Commentary } \\
\text { hallucinations }\end{array}$ & Present & None & $\begin{array}{l}\text { One prolonged } \\
\text { episode (responsive to } \\
\text { medication) }\end{array}$ & $8 \mathrm{mths}$ \\
\hline
\end{tabular}

epilepsy, a standardised en bloc resection involves excision of the anterior part of the anterior part of the temporal lobetypically extending $3.5 \mathrm{~cm}$ from the tip of the temporal lobe on the left and $4.5 \mathrm{~cm}$ on the right. A small number of patients had selective amygdalo-hippocampectomy in which the resection was limited to the mesial structures.

Follow up assessments are routinely conducted at 2, 6, and 12 months postoperatively. Further appointments are usually then made annually or more frequently, according to clinical need. All of the patients who developed chronic psychosis postoperatively received specialist neuropsychiatric evaluation and all but one were hospitalised in a specialist neuropsychiatric unit at the Maudsley Hospital. Such patients are typically followed up at this centre until stable where practical or by another regional neuropsychiatric unit.

\section{Cases}

The cases met the DSM-IV diagnosis of a psychotic disorder due to a general medical condition, specifically fulfilling the criteria for schizophrenia. We thus excluded three subjects who had purely postictal psychosis, which tended to be of short duration and two subjects with affective psychoses. All data were entered into OPCRIT (operational criteria for psychotic and affective illness), a well validated operationalised diagnostic tool to establish the diagnosis which would be reached if the presence of epilepsy and surgery were discounted. ${ }^{21} 22$ This enabled a check that the psychoses were indeed "schizophrenia-like".

For each case the next three consecutive patients who had a temporal lobectomy but did not develop psychosis were selected as controls. Two potential postoperative psychotic subjects and eight controls were excluded due to insufficient data.

\section{Neuroimaging}

Many of the subjects had their operations before the advent of clinical magnetic resonance imaging (MRI) and thus structural analyses were confined to postoperative imaging. This was obtained for seven subjects in the psychotic group and 21 subjects in the non-psychotic group. Images were obtained on a 1.5 Tesla GE N/Vi Signa System (General Electric, Milwaukee, MI, USA) scanner using a 3-D inversion recovery. Prepared fast spoiled GRASS T1-weighted dataset was obtained in the coronal plane with $1.5 \mathrm{~mm}$ contiguous sections. The volumes of the amygdala and hippocampus of the unoperated side were measured by two independent raters using criteria developed by Watson et al and adjusted for total intracranial volume.23 The posterior to anterior distribution of the hippocampus and amygdala were presented graphically. Interrater reliabilities for the volumetric analyses (expressed as intraclass correlations) were 0.94 for the amygdala, 0.98 for the hippocampus, and 0.97 for total intracranial volume.

Ethical approval was obtained from the Ethics Committee of the Institute of Psychiatry.

\section{Statistical analysis}

To identify potential risk factors for the development of psychosis, odds ratios (ORs) with 95\% confidence intervals (CIs) were calculated for dichotomous categorical variables, and the $\chi^{2}$ test applied to non-dichotomous categorical variables. Continuous variables were analysed using $t$-tests. 


\section{RESULTS}

\section{Demographic and clinical details}

Eleven patients were identified who developed de novo postoperative schizophrenia-like psychotic disorders (see table 1). The disorders were dominated by persecutory delusions and auditory hallucinations; thought disorder was present in six and schneiderian first rank symptoms present in five patients. Negative symptoms were infrequent, and although subjects often showed affective symptoms these did not dominate the clinical presentation.

There was little evidence of any association between postoperative seizure activity and the development of psychotic symptoms (see table 2). Of the six subjects who had persistent seizures, only one showed a clear worsening of his chronic psychotic symptoms postictally. There were no associations between symptoms and demographic or clinical features such as the aetiology, type, and duration of the epilepsy or side, extent, or outcome of the operation.

Table 3 shows the anticonvulsant treatment that patients were taking at the time of the development of the psychotic symptoms. Nearly all subjects were taking the same medication in the period before their operation and in only one case (subject P2) had an alteration in medication preceded the development of psychosis (the withdrawal of adjunctive agents). Blood levels of medication in the postoperative period were available for seven of the subjects and all were within the therapeutic range with no cases of toxicity.

There was a close temporal link between the recurrence of seizures postoperatively and the first appearance of psychotic symptoms in two subjects. In the remainder either the psychosis arose despite cessation of clinically overt seizures or there was a long time difference between the recurrence of seizures and onset of psychosis. Fluctuations in the course of the schizophrenia-like psychosis were closely related to ongoing seizure activity in only one patient.

The postoperative EEG abnormalities among the psychotic patients whose seizures persisted postoperatively showed clear epileptiform activity. These abnormalities were typically similar to the abnormalities seen preoperatively, with the focus of activity shifting anterior or posterior to the excised region. In one case there was a clear increase in the epileptiform activity in the side contralateral to the excised lobe. Three of the five psychotic patients who experienced a cessation of seizure activity had no definite epileptiform activity on EEG recordings (sleep and wake surface EEGs in all cases). The other two patients who had no recurrence of seizures showed some EEG anomalies. Subject P3's tracing

Table 2 Details of epilepsy and underlying pathology in the 11 subjects

\begin{tabular}{|c|c|c|c|c|}
\hline Subject & $\begin{array}{l}\text { Age of onset of } \\
\text { habitual } \\
\text { seizures(years) }\end{array}$ & $\begin{array}{l}\text { Side of } \\
\text { operation }\end{array}$ & $\begin{array}{l}\text { Preoperative } \\
\text { EEG } \\
\text { abnormalities }\end{array}$ & Pathology \\
\hline P1 & 3 & L & Unilateral & MTS \\
\hline P2 & 8 & $\mathrm{R}$ & Bilateral & $\begin{array}{l}\text { Vascular } \\
\text { hamartoma }\end{array}$ \\
\hline P3 & 9 & $\mathrm{R}$ & Unilateral & MTS \\
\hline P4 & 12 & $\mathrm{~L}$ & Unilateral & DNET \\
\hline P5 & 23 & $\mathrm{~L}$ & Bilateral & $\begin{array}{l}\text { No definite } \\
\text { pathology }\end{array}$ \\
\hline P6 & 3 & $\mathrm{R}$ & Bilateral & MTS \\
\hline P7 & 2 & $\mathrm{R}$ & Bilateral & $\begin{array}{l}\text { No definite } \\
\text { pathology }\end{array}$ \\
\hline P8 & 19 & $\mathrm{R}$ & Unilateral & Abscess \\
\hline P9 & 6 & $\mathrm{~L}$ & Bilateral & MTS \\
\hline P10 & 14 & $\mathrm{R}$ & Bilateral & Ganglioglioma \\
\hline P11 & 7 & $\mathrm{R}$ & Unilateral & DNET \\
\hline
\end{tabular}

EEG, electroencephalogram; L, left; R, right; MTS, mesial temporal sclerosis; DNET, dysembryoblastic neuroepithelial tumour. demonstrated very infrequent sharp waves in the region of the excised temporal lobe. Subject P9, who had no clinically overt seizure activity, had however a highly abnormal EEG, which was taken while she was experiencing psychotic symptoms. The abnormalities were not thought to be attributable to her medication at the time of the recording, which included pimozide.

\section{Relationship of the psychosis to operation}

As can be seen from fig l, eight patients developed their initial symptoms within a year of the operation.

\section{Risk factors}

None of the demographic, neuropsychological, or operative variables studied differentiated those who developed psychosis postoperatively from those who did not (see table 4). However, it emerged that psychotic patients were more likely to have pathologies other than mesial temporal sclerosis identified in the resected tissue (with the entire 95\% CI of the odds of having a pathology other than sclerosis lying above 1.0). The psychotic patients were also more likely to have had bilateral EEG abnormalities on their preoperative EEGs.

The only neuroanatomical difference between the groups on the postoperative MRI was a significantly smaller amygdala on the unoperated side (fig 2).

\section{DISCUSSION}

We report on 11 patients who, following surgical treatment for epilepsy, developed de novo psychotic illnesses which phenomenologically resembled schizophrenia with persistent persecutory delusions, auditory hallucinations, and, in some cases, schneiderian first rank symptoms. Negative symptoms were not prominent, although this could in part reflect the length of the follow up period. We did not confirm previously reported associations between particular psychotic symptoms and clinical features such as the age of onset of epilepsy. Although as in previous reports the majority of the patients had right sided temporal lobectomies this did not emerge as a significant risk factor for the development of psychosis. ${ }^{19}$

Blumer et al have recently argued that there is a causal link between temporal lobectomy and psychosis. ${ }^{12}$ Our confirmation of a clustering of cases of new onset psychosis in the year after the operation appears to support this position. However, part of the association could arise from factors such as the age of operation. The mean age of operation in our subjects was 25 years which lies near the peak age onset of schizophrenia. ${ }^{24}$ In the cohort of patients who underwent temporal lobectomy from 1978 to 2001 there were also seven subjects who were psychotic prior to the operation (details available from PS), and the median age of onset of their psychosis at 26 years did not differ significantly from that of the postoperative psychotic group. The only difference between the groups was in the later age at operation of 32 years among those who were psychotic prior to surgery. It seems most likely that the operation acts as a stressor, precipitating psychosis in vulnerable subjects during a high risk period.

The presence of pathologies other than mesial temporal sclerosis emerged as a significant risk factor for the development of postoperative psychosis. The prominence of congenital lesions such as dysembryoblastic neuroepithelial tumours and gangliogliomas has been reported by other groups. ${ }^{6}{ }^{1325}$ The significance of this association is unclear but it could reflect the presence of aberrant prenatal neurodevelopment which may contribute to a vulnerability to the development of a psychotic disorder in adult life.

Our results echo other findings implicating bilateral abnormalities in the pathogenesis of postlobectomy psychosis. Functionally, this is apparent from our finding of higher 
Table 3 Relationship between postoperative seizures and psychotic symptoms and details of EEG abnormalities

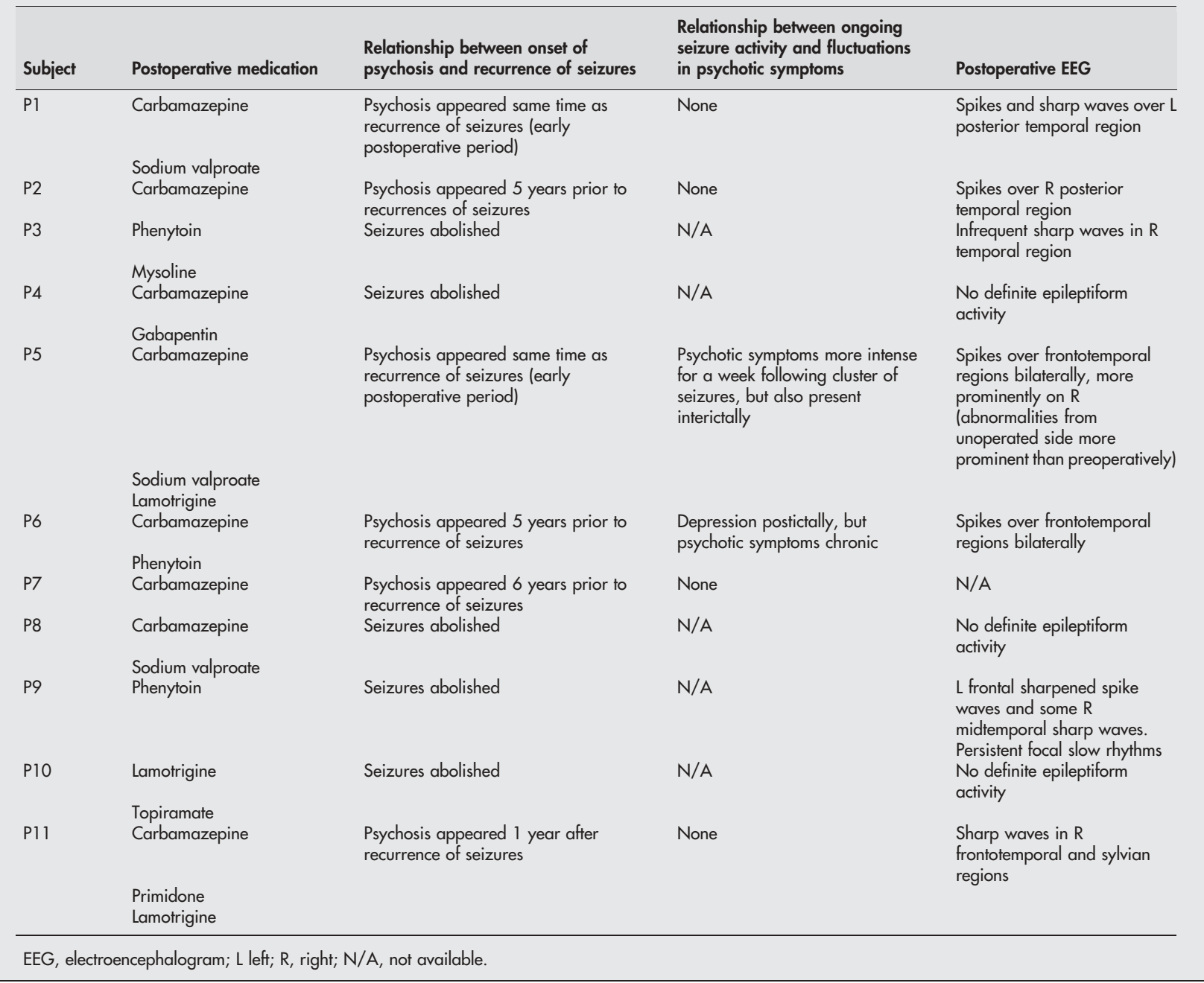

rates of preoperative bilateral EEG abnormalities. The presence of preoperative bilateral EEG anomalies in this group has been reported by others ${ }^{4}$ and the postoperative emergence of new seizures from the unoperated lobe has been found to be associated with de novo episodic postictal psychosis. $^{15}$ A similar clear temporal link between the

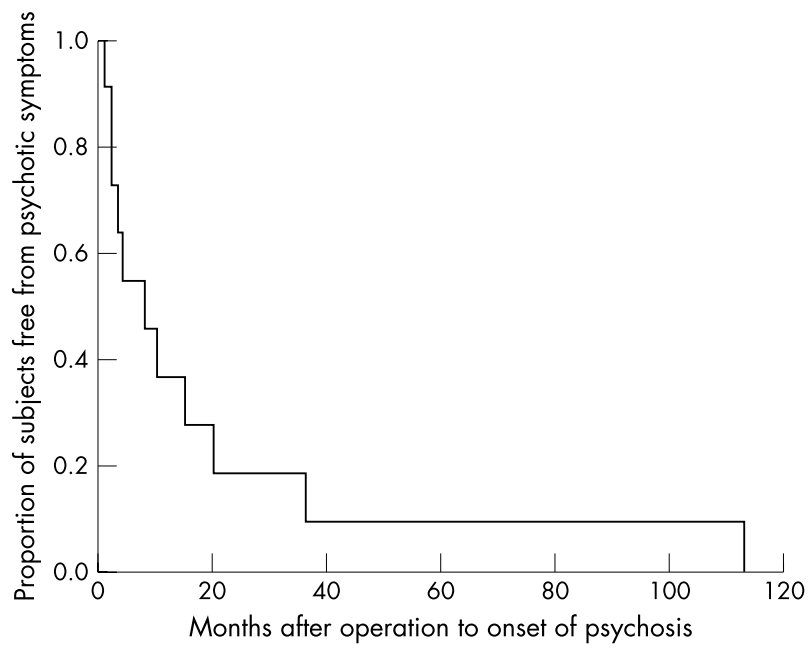

Figure 1 Time in months from the operation until the onset of psychotic symptoms. recurrence of seizures and onset of de novo chronic psychotic symptoms was apparent in only two of the patients. In both cases the seizures were similar in semiology to preoperative seizures, although an increase in abnormal epileptiform activity in the unoperated lobe was noted in one patient. Additionally there is no simple link between ongoing seizure activity and fluctuations in the intensity of the chronic psychotic symptoms. Only one patient showed a definite deterioration in psychotic symptoms following a cluster of seizures and none of the patients demonstrated an alternating pattern of seizure remittance and psychotic exacerbations.

It is also possible that subclinical ictal activity-either ipsilateral or contralateral to the excised lobe-may contribute to the development of psychosis. Among the five subjects who had no clinically overt seizure activity two had abnormal EEGs-which in one case were relatively minor but in the other included bilateral frontal sharp waves and focal slow rhythms. Although it is plausible that in this subject the subclinical ictal activity may have contributed to the onset and maintenance of psychotic symptoms, this would appear to be an exceptional case.

The functional bilateral abnormalities are complemented by the evidence we report for specific bilateral structural abnormalities, reflected in the decreased volume of the amygdala on the unoperated side. Another recent study emphasised the possible pathogenic role of the amygdala in the psychoses of epilepsy, however, this study found an 
Table 4 Risk factors for the development of postoperative schizophrenia-like psychosis

\begin{tabular}{|c|c|c|c|}
\hline & $\begin{array}{l}\text { Patients who developed } \\
\text { psychosis after TL }\end{array}$ & $\begin{array}{l}\text { Patients free of psychosis } \\
\text { after TL }\end{array}$ & Test of significance \\
\hline \multicolumn{4}{|l|}{ Demographic factors } \\
\hline \multicolumn{4}{|l|}{ Sex } \\
\hline Male & 5 & 20 & OR (male) 0.54 (95\% Cl 0.13 to 2.14 ) \\
\hline Female & 6 & 13 & \\
\hline Age at operation (mean (SD)) & $25(8)$ & $27(8)$ & $t=-0.63, \mathrm{df} 42, p=0.53$ \\
\hline Follow up in years (mean (SD)) & $8(5)$ & $10(6)$ & $t=-0.89, \mathrm{df} 42, \mathrm{p}=0.37$ \\
\hline \multicolumn{4}{|l|}{ Neuropsychological factors } \\
\hline \multicolumn{4}{|l|}{ Handedness } \\
\hline Right & 10 & 28 & $\chi^{2}=1.14, \mathrm{df} 2, p=0.56$ \\
\hline Left & 1 & 2 & \\
\hline Ambidextrous & 0 & 3 & \\
\hline \multicolumn{4}{|l|}{$I Q$} \\
\hline Verbal & $93(18)$ & $96(13)$ & $t=-0.51, \mathrm{df} 42, p=0.61$ \\
\hline Performance & $95(20)$ & $96(12)$ & $t=-0.16, d f 42, p=0.87$ \\
\hline \multicolumn{4}{|l|}{ Clinical factors } \\
\hline $\begin{array}{l}\text { Age in years of onset of habitual seizures } \\
\text { (mean (SD)) }\end{array}$ & $10(7)$ & $9(6)$ & $t=-0.25, d f 42, p=0.80$ \\
\hline History of febrile convulsions & 3 & 7 & $\begin{array}{l}\text { OR (history of febrile convulsions) } 1.39 \\
(95 \% \mathrm{Cl} 0.29 \text { to } 6.6 \text { ) }\end{array}$ \\
\hline History of status epilepticus & 2 & 2 & OR (status) 3.4 ( $95 \% \mathrm{Cl} 0.42$ to 28.1 ) \\
\hline \multicolumn{4}{|l|}{ Preoperative EEG findings } \\
\hline Unilateral abnormalities & 4 & 25 & $\begin{array}{l}\text { OR (bilateral abnormalities) } 5.45 \text { (95\% } \\
\text { Cl } 1.26 \text { to } 23.6 \text { ) }\end{array}$ \\
\hline Bilateral abnormalities & 7 & 8 & \\
\hline \multicolumn{4}{|l|}{ Operation } \\
\hline \multicolumn{4}{|l|}{ Side } \\
\hline Right & 7 & 16 & OR (right side) 1.6 (95\% Cl 0.4 to 6.4 ) \\
\hline Left & 4 & 17 & \\
\hline \multicolumn{4}{|l|}{ Extent } \\
\hline Anterior temporal lobectomy & 9 & 32 & $\begin{array}{l}\text { OR (temporal lobectomy) } 0.14 \text { (95\% Cl } \\
0.13 \text { to } 1.73 \text { ) }\end{array}$ \\
\hline Amygdalo-hippocampectomy & 2 & 1 & \\
\hline \multicolumn{4}{|l|}{ Outcome } \\
\hline Total cessation of seizures & 5 & 23 & $\begin{array}{l}\text { OR (complete cessation) } 0.36(95 \% \mathrm{Cl} \\
0.08 \text { to } 1.45)\end{array}$ \\
\hline Partial improvement & 1 & 4 & \\
\hline \multirow{2}{*}{\multicolumn{4}{|c|}{$\begin{array}{l}\text { Pathology } \\
\text { Provement }\end{array}$}} \\
\hline & & & \\
\hline Mesial temporal sclerosis & 4 & 25 & $\begin{array}{l}\text { OR (of pathologies other than mesial } \\
\text { temporal sclerosis) } 5.46 \text { ( } 95 \% \mathrm{Cl} 1.26 \text { to } \\
\text { 23.6) }\end{array}$ \\
\hline \multicolumn{4}{|r|}{$20.0 / 1$} \\
\hline Dysembryoblastic neuroepithelial tumours & 2 & 1 & \\
\hline No definite abnormality & 2 & 4 & \\
\hline Arteriovenous malformation & 0 & 1 & \\
\hline Cavernous haemangioma & 1 & 0 & \\
\hline Abscess & 1 & 0 & \\
\hline Ganglioglioma & 1 & 2 & \\
\hline
\end{tabular}

enlargement of the amygdala. ${ }^{26}$ The discrepancy may reflect differences in the study populations as we included only surgically treated subjects who form a small and distinct group among all those with epilepsy and psychosis. Several strands of research implicate abnormalities of the amygdala in the pathogenesis of schizophrenia. Structurally, there are consistent reports using volumetric MRI of a more marked decline in the volume of the amygdala in patients with schizophrenia compared with other brain structures. ${ }^{27}$ Some of the negative symptoms of schizophrenia such as flattened affect, thought disorder and abnormal processing of emotionally salient material have been linked to amygdala dysfunction. ${ }^{28-31}$ In view of this evidence it is possible that among subjects who have a temporal lobectomy, if the remaining amygdala is structurally and functionally abnormal this may have critical effect, precipitating a chronic psychotic disorder.

There are several limitations to the study. Although all subjects underwent an intensive preoperative investigations and prolonged follow up, it is possible that some control subjects may have had undetected psychotic disorders. There were also some candidate cases and control subjects who were lost to follow up, although given the small numbers of such subjects their data are unlikely to influence the pattern of results greatly. The risk factors we examined were not exhaustive and had a bias towards biological variables. In the future we aim to collect data on the potentially critical variable of family history of mental illness using reliable techniques. We also did not systematically examine the possibility that psychosocial variables such as socioeconomic class may be risk factors for the development of psychosis. Similarly we do not have data on the psychosocial outcome of patients although the clinical impression is of an almost uniformly poor outcome among the group who developed psychosis (particularly if seizures persisted) compared with those who remained free of psychosis.

It is unlikely that the psychoses developed as a result of psychotogenic anticonvulsant medication as drugs are typically not changed in the first year after a lobectomy, which is the peak risk period for the development of psychosis. There was only one case in which an alteration of medication (the withdrawal of lamotrigine) preceded the onset of psychosis. Iatrogenic psychosis secondary to anticonvulsant toxicity is also unlikely in our cases as serum anticonvulsant levels during the postoperative period were all within the therapeutic range (although results were not 

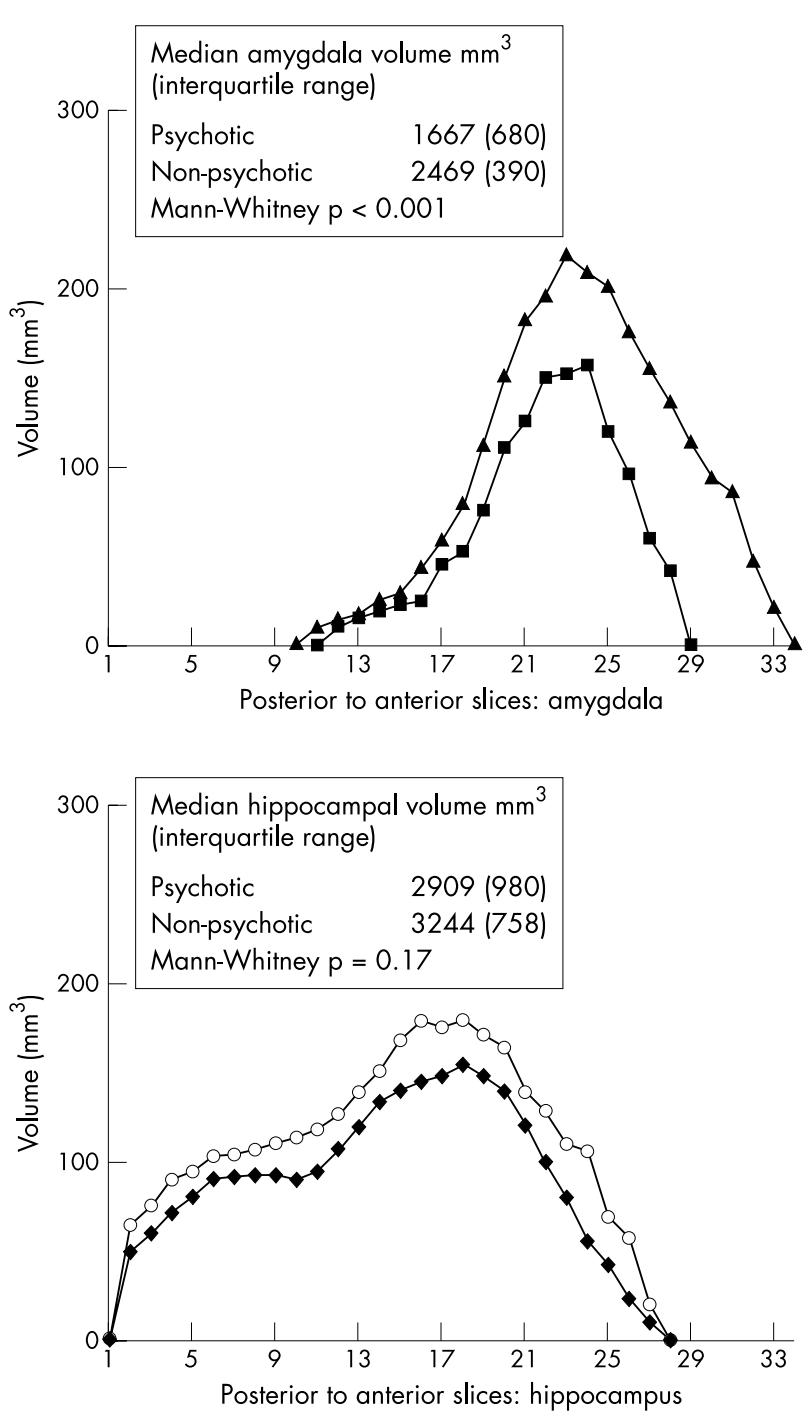

Figure 2 Posterior to anterior coronal slice by slice volumes of the amygdala (top graph) and the hippocampus (bottom graph) on the unoperated side in patients who developed psychosis and those who remained free from psychosis. The volume of the amygdala on the unoperated side was significantly smaller among the patients who became psychotic following temporal lobectomy $(\boldsymbol{\square})$ compared with the patients who remained free of psychosis $(\mathbf{\Delta})$. There was no significant difference between the volume of the hippocampus for the psychotic group $(\diamond)$ and non-psychotic group $(0)$.

available on all cases). Additionally the case definition excluded patients whose psychosis occurred in the context of an acute organic brain syndrome.

Our study identifies both the characteristics of those patients at greatest risk for the development of schizophrenialike psychosis following a temporal lobectomy and also the period of greatest risk. This may aid in the early identification and treatment of those who develop de novo psychotic disorders. We also find that bilateral temporal lobe abnormalities, particularly of the amygdala, may form part of the neural substrate of this disorder.

\section{Authors' affiliations}

P Shaw, M Henderson, A S David, B K Toone, Departments of Psychological Medicine, Institute of Psychiatry and Guy's, King's and St Thomas' Medical School, London, UK
J Mellers, Maudsley Hospital, London, UK

C Polkey, Department of Neurosurgery, King's College Hospital, London, UK

Competing interests: none declared

\section{REFERENCES}

1 Simmel ML, Counts S. Clinical and psychological results of anterior temporal lobectomy in patients with psychomotor epilepsy. In: Baldwin M, Bailey P, eds. Temporal lobe epilepsy. Springfield IL: Charles Thomas, 1958:530-50.

2 Serafetinides ES, Falconer MA. The effects of temporal lobectomy in epileptic patients with psychosis. J Ment Sci 1962;108:584-93.

3 Jensen I, Larsen JK. Psychoses in drug-resistant temporal lobe epilepsy. J Neurol Neurosurg Psychiatry 1979;42:948-54.

4 Stevens JR. Psychiatric consequences of temporal lobectomy for intractable seizures: a 20-30-year follow-up of 14 cases. Psychol Med 1990;20:529-45.

5 Polkey C. Effects of anterior temproal lobectomy apart from the relief of seizures. J R Soc Med 1983;76:354-8.

6 Bruton CJ. The neuropathology of temporal lobe epilepsy. Maudsley Monographs no. 31. Oxford: Oxford University Press, 1988.

7 Guldvog B, Loyning Y, Hauglie-Hanssen E, et al. Surgical versus medical treatment for epilepsy. I. Outcome related to survival, seizures, and neurologic deficit. Epilepsia 1991;32:375-88.

8 Bladin PF. Psychosocial difficulties and outcome after temporal lobectomy Epilepsia 1992;33:898-907.

9 Leinonen E, Tuunainen A, Lepola U. Postoperative psychoses in epileptic patients after temporal lobectomy. Acta Neurol Scand 1994;90:394-9.

10 Mace CJ, Trimble MR. Psychosis following temporal lobe surgery: a report of six cases. J Neurol Neurosurg Psychiatry 1991;54:639-44.

11 Manchanda R, Miller H, McLachlan RS. Post-ictal psychosis after right temporal lobectomy. J Neurol Neurosurg Psychiatry 1993;56:277-9.

12 Blumer D, Wakhlu S, Davies K, et al. Psychiatric outcome of temporal lobectomy for epilepsy: incidence and treatment of psychiatric complications. Epilepsia 1998:39:478-86.

13 Andermann LF, Savard G, Meencke HJ, et al. Psychosis after resection of ganglioglioma or DNET: evidence for an association. Epilepsia 1999;40:83-7.

14 Inove $Y$, Mihara T. Psychiatric disorders before and after surgery for epilepsy. Epilepsia 2001;42(suppl 6):13-18.

15 Christodoulou C, Koutroumanidis M, Hennessy MJ, et al. Postictal psychosis after temporal lobectomy. Neurology 2002;59:1432-5.

16 Mayanagi Y, Watanabe E, Nagahori Y, et al. Psychiatric and neuropsychological problems in epilepsy surgery: analysis of 100 cases that underwent surgery. Epilepsia 2001;42(suppl 6):19-23.

17 Roberts GW, Done DJ, Bruton C, et al. A "mock up" of schizophrenia: temporal lobe epilepsy and schizophrenia-like psychosis. Biol Psychiatry 1990;28:127-43.

18 Jensen I, Larsen JK. Mental aspects of temporal lobe epilepsy. Follow-up of 74 patients after resection of a temporal lobe. I Neurol Neurosurg Psychiatry 1979;42:256-65.

19 Matsuura M. Psychosis of epilepsy, with special reference to anterior temporal lobectomy. Epilepsia 1997;38(suppl 6):32-4.

20 Koutroumanidis M, Hennessy MJ, Seed PT, et al. Significance of interictal bilateral temporal hypometabolism in temporal lobe epilepsy. Neurology 2000;54:1811-21.

21 Craddock M, Asherson P, Owen MJ, et al. Concurrent validity of the OPCRIT diagnostic system. Comparison of OPCRIT diagnoses with consensus bestestimate lifetime diagnoses. Br J Psychiatry 1996;169:58-63.

22 Williams J, Farmer $A E$, Ackenheil $M$, et al. A multicentre inter-rater reliability study using the OPCRIT computerized diagnostic system. Psychol Med 1996;26:775-83.

23 Watson C, Andermann F, Gloor P, et al. Anatomic basis of amygdaloid and hippocampal volume measurement by magnetic resonance imaging. Neurology 1992:42:1743-50.

24 Di Maggio C, Martinez M, Menard JF, et al. Evidence of a cohort effect for age at onset of schizophrenia [Comment]. Am J Psychiatry 2001; 158:489-92.

25 Jensen I, Vaernet K. Temporal lobe epilepsy. Follow-up investigation of 74 temporal lobe resected patients. Acta Neurochir (Wein) 1977;37:173-200.

26 Tebartz VE, Baeumer D, Lemieux L, et al. Amygdala pathology in psychosis of epilepsy: A magnetic resonance imaging study in patients with temporal lobe epilepsy. Brain 2002;125:1-9.

27 Lawrie SM, Abukmeil SS. Brain abnormality in schizophrenia. A systematic and quantitative review of volumetric magnetic resonance imaging studies [Comment]. [Review] [54 refs]. Br J Psychiatry 1998;172:110-20.

28 Benes FM. Schizophrenia, II: amygdalar fiber alteration as etiology? Am J Psychiatry 2003;160:1053.

29 Benes FM. Emerging principles of altered neural circuitry in schizophrenia. [Review] [183 refs]. Brain Res Brain Res Rev 2000;31:251-69.

30 Fudge JL, Emiliano $A B$. The extended amygdala and the dopamine system: another piece of the dopamine puzzle. J Neuropsychiatry Clin Neurosci 2003; 15:306-16.

31 Rajarethinam R, DeQuardo JR, Miedler J, et al. Hippocampus and amygdala in schizophrenia: assessment of the relationship of neuroanatomy to psychopathology. Psychiatry Res 2001;108:79-87. 